would seem to be indisputable, then, that the American people are satisfied with their buildings if the outsides are good-looking. The structures illustrated in the Record and Guide include private residences, apartment-houses, hotels, warehouses, and churches, any one of which must have required some ingenuity in arrangement of plan, and have had some interesting constructive details, but they are carefully hidden from those who should be interested in these essential portions of architecture.

These indications of the tendency of American architecture show very clearly where the error is. The needs of the public are heeded in almost every phase of modern life and thought. The manufacturer and the shop-keeper, not less than the editor and the artist, are continually on the lookout for what the public wants, and hasten to supply them as soon as manifested. The public evidently want only exteriors in architecture. Plans, use, environment, and other matters which were once pre-eminent in the art, are now at a discount. Until the popular mind frees itself from such erroneous ideas, it will be impossible for the art to make any progress. It is well to remember that the general public which is satisfied with such things is more to blame for their continuance than the architects who prepare the designs; but it is a serious retrogression when the architects join the popular movement, and give their assent and support to it by catering to its most objectionable features.

School of Architecture, University of Pennsylvania, Jan. 8.

Cyclones and Anticyclones.

IT seems to me that the discussion in regard to the origin of cyclones and anticyclones that has been in progress in Science and other journals for several months past opens up a question that has so long been regarded as settled, that it seems impossible to look upon it as being in doubt. It is, in short, as to whether gravitation is the chief cause of movements of the air. Barometric observations have directed attention so forcibly to the relative weights of columns of air in storm-centres and elsewhere, that it has been assumed as a matter of course that the pressure gradients thus made manifest are the occasion of the horizontal movement apparent as wind. If this be the true explanation, in order that such horizontal movement may continue, it is necessary that there be a corresponding vertical movement, and that it be sustained by adequate renewal of the buoyancy of the air in the proper localities. This renewal of buoyancy can only be accomplished, so far as our knowledge at present extends, by heating. But now we are informed as a matter of fact that the air at anticyclonic centres descends in spite of its being warmer at an elevation, and in like manner above cyclonic centres fails to descend, although colder than at the surface of the earth. This certainly opens up the entire question as to whether there is ascensional movement at storm-centres commensurate with the extent and velocity of the winds blowing horizontally, and supposed to be due to an indraught; or, in other words, whether gravitation really plays the part that has been tacitly assigned to it, or whether it must be relegated to a subordinate position. Personally I am very glad indeed that a discussion having such bearings has come up at this particular juncture, because it has increased very decidedly my interest in following certain clews that look promising in regard to the effects of variations of the earth's magnetic condition as a whole.

Lyons, N.Y., Jan. 5.

M. A. VEEDER.

\section{Dr. Hann and the Condensation Theory of Storms.}

THE time has not yet come for a review of the various discussions upon this subject that have been published during the past four years. I doubt if there has ever been a better illustration, in the history of meteorology, of the absolute necessity there exists of appealing to observations in order to establish intricate theories, than the recent discussions on the reversal of temperature in our storms and "highs," which is but another way of putting the problem before us. In this very line Professor Davis says (Science, Jan. 2), "Records of temperature made on high mountain-peaks furnish the best means of testing the convectional theory of cyclones; for, even if all other tests were successfully borne, failure under this test would be fatal to the theory." This statement of the case should be received with a little caution, however, because the presence of the mountain must be a modifying cause, and oftentimes there are cases in which some part of the storm, or high, has its action below the mountain-peaks (I have found this true especially at Pike's Peak); but the larger commotions of the atmosphere may be profitably studied at such points.

In carrying out my studies on this problem, I have invariably sought for help from the original records, which are now so abundant at Mount Washington, Pike's Peak, and at many high stations in Europe, and I have massed thousands of observations bearing on the question. The first publication of these studies was in the American Meteorological Journal of August, 1886, in which I showed that the temperature observations at the base and summit of Pic du Midi, in France, indicated a decided rise at both points on the approach of a storm. In October of the following year I showed by the observations at Mount Washington that in both storms and highs there was the same fluctuation at the summit as on the base, and that the mean temperature of the air-column was ten to twelve degrees higher in storms, and the same amount lower in highs, than before or after the centre had passed.

It seems to me that the crucial test in Dr. Hann's recent work, which has attracted so much attention, must be the records at the mountain stations, and I believe that this will be insisted on by Dr. Hann himself as strongly as by any one. In fact, Dr. Hann has based all his work on his interpretation of the records.

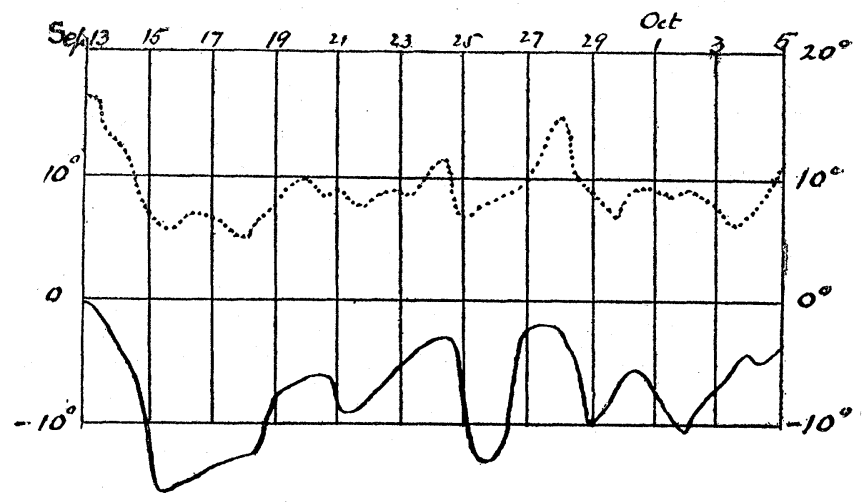

TEMPERATURE FLUCTUATIONS, 1889.

Sonnblick, full curve; Salzburg, dotted curve.

It seems to me that he bas given altogether too much weight to a few isolated cases, while he has ignored hundreds of cases which disprove his propositions. I have already shown in this journal for Sept. 5, 1890, that the evidence at Sonnblick is different only in degree from that in this country, and I have there explained how the peculiar results in the remarkable high of barometer, 1889 (which, in fact, was the only one in three years exhibiting such discordances from the usual law), might be accounted for. I have now made a special study of the storm of Oct. 1, 1889, which Dr. Hann advanced as favoring his view, that the temperature in a storm falls as we rise in its centre, and at some height is lower than that of the surrounding region. The results of this investigation so remarkably corroborate my position, that I present a copy of the curves in order that others may see the exact state of the case.

These curves are constructed as follows. The lower or full curve represents the temperature observation for each day at Sonnblick, 3,095 metres (10,154 feet), at 9 P.M., at which time very nearly the mean for the tw enty-four hours occurs; and the upper or dotted curve shows the te mperature at precisely the same time at Salzburg, just north of Sonnblick, at a height of $43 \%$ metres $(1,434$ feet). I have given the curves from Sept. 13 to Oct. 5, including the storm of the 1st. It will be seen that there is a most remarkable accordance between these curves; almost every bending at the base is faithfully reproduced at the summit; and, if any thingr, there is generally a greater fluctuation on the mountain than ore the plain. This is not all, however. Examining the very date under discussion, Oct. 1, we find that at Sonnblick the temperature began rising on Sept. 29, and in twenty-four hours had risen 
$4.2^{\circ} \mathrm{C} .\left(7.6^{\circ} \mathrm{F}.\right)$; in the next twenty-four hours it fell $1.4^{\circ}\left(2.5^{\circ} \mathrm{F}.\right)$, and then fell $3.2^{\circ}\left(5.8^{\circ} \mathrm{F}\right.$.), or a fall of $8.3^{\circ} \mathrm{F}$. in forty-eight hours. It seems to me that no more positive disproof of Dr. Hann's position could be found than these very observations which have given rise to so much discussion. Here is the temperature higher in the centre of a storm than before and after it, both at base and summit, exactly in accordance with theory, and directly opposed to Dr, Hann's position.

Dr. Hann has tried to fortify his position by stating the fact that in this storm the average temperature was $4^{\circ} \mathrm{C}$. below the thirty-years' normal, and this temperature was lower than that in a high nearly two months later. As I showed in this journal for June 6, 1890, " the temperature in a vertical direction in a storm is not fixed, but may be ten degrees, or even more, lowèr than the average, and yet be many degrees above that of the surrounding region. That the temperature in an October storm was lower than in a November high area is not in any wise remarkable." This position is exactly the one taken more recently by Professor Ferrel (Science, Dec. 19); so that we see that on all accounts Dr. Hann's position is entirely untenable, and his disproof of the condensation theory, if it amounts to any thing, is a direct proof in its favor, as shown by the records.

H. A. HAZEN.

Washington, Jan. 7.

The Practicability of transporting the Negro back to Africa.

A LITTLE more than a year ago there appeared in the columns of The Open Court of Chicago some very excellent articles upon the question as to the methods we should adopt in handling our African population in the future. There were two sides taken in the premises, - those in favor of making the attempt to assimilate this mighty host of millions of negroes we now have in our midst; and those in favor of sending him back to the land of his ancestors. In the opinion of the present writer, the most able of all these articles came from the pen of Professor Cope, and in the main we completely coincide with the views that that far-seeing thinker puts forth.

Professor Cope's reasons for returning the African to Africa are most cogent indeed, and are stated in a philosophic and masterly manner. He lifts himself far above the state of the case as seen by the short-sighted party politician, or the sentimental hopes of the idealist or philanthropist, and, calling history and science to his aid, shows most conclusively that we incur a great danger in quietly submitting to the continued presence of this race of people among us. It is not my object here to enlarge upon his ably stated argument, for he has shown with marked precision and strength the dangers of hybridization of the white and black races in this courtry, and the constantly disturbing element the negro is in our national organization. By far the greatest danger, however, comes from the mixture of the two races; and that such is now going on, one has to but study the population of a city like Washington to appreciate.

It is to be most devoutly hoped that in the very near future the pressing necessity of taking early action in this matter will be fully recognized; and, when such comes to be the case, the practical question will surely arise as to the best ways and means of accomplishing the transfer. Little has been written upon this point as yet, though we all know that the proper exercise of ability, of energy, and the use of sufficient money, will effect it. It seems to me that the first steps that should be taken are those of an organization of an extensive American expedition to Africa, to primarily report upon the best available areas for colonization, taking conditions of climate and for future improvement into consideration. Such an expedition would have many decided advantages; for, in addition to making a well-organized initial move for the removal of the negro to his proper home, it would give America an opportunity to reap the national benefits that flow from such exploration,- credit of a nature that we now stand greatly in need of, as our last African expedition was practically a puerile failure. Finally, it would give scientific employment to several of the huge and expensive battle-ships we are now constructing, and for which there is no other especial employment in these days of peace, beyond an exhibition of power.
The next step should be in the direction of constructing a suffcient number of comfortable and commodious steamers by means of which the transfer could be made; and upon their completion, the necessary national legislation should be promptly enacted that would efficiently result in the removal of every negro in this country to those parts of the African continent selected for them. The settlement for such personal properties as the comparatively few negroes could justly lay claim to in the United States could be easily settled. It would not create a circumstance aside similar financial problems that we have most promptly and satisfactorily solved in former times.

We do not need the negro vote; we do not need his labor; and, least of all, do we need the injection of his lowly blood into our veins. On the other hand, "Darkest Africa" can well stand, and with the greatest benefit, the introduction into her fertile valleys and upon her fair hillsides, of the very material she most requires to inaugurate her development; that is, several millions of the descendants of her people, which, for a century and a half, have enjoyed the tuition of the most highly civilized race upon the face of the globe.

Takoma, D.C., Jan. 2

R. W. SHUFELDT.

["Letters to Editor" continued on p. 50.]

NOTES AND NEWS.

AN exhibition at Grolier Club, 29 East 32d Street, New York, of books on alchemy and early chemistry belonging to Dr. H. C. Bolton, is announced to close Monday, Jan 26; open afternoons from two to six o'clock.

-Dr. Don José Nicolas Gutierrez, founder of the Cuban Academy of Medical, Physical, and Natural Sciences at Havana, died Dec. 31,1890 , at the age of ninety. The rector of the university, and Professor Poey of the same, still live,- - one at the age of ninety, the other ninety-one.

-Owing to their greatiy increased trade in New York, George L. English \& Co., mineralogists, have leased rooms at 733 and 735 Broadway (within three doors of their former location), in which they have more space than heretofore in their Philadelphia and New York stores combined. The consolidation of the two stores, and the formal transfer of the business, were made on Jan. 1. Mr. Niven, a member of the firm, started Dec. 13 on another collecting-trip to the South-west and Mexico.

-The question has been asked, "Does the weather of Kansas divide itself into seven-year wet and dry periods?" Another question that has been asked, and it is an important one too, is, "Is the rainfall of Kansas increasing?" And it is the object of a paper by E. C. Murphy, C.E., Kansas University, Lawrence, Kan., to answer these questions as correctly as the rainfall records of the State will permit, in which he concludes from the record of the observations thus far taken, that the law of sevenyear wet and dry periods does hold in Kansas, and also that the rainfall is steadily increasing in Kansas.

- The next meeting of the American Branch of the Society for Psychical Research will be held at the Association Hall, corner of Berkeley and Boylston Streets, Boston, Mass., on Tuesday, Jan. 27, at 8 P.M. The following papers will be read: "Report of Some Recent Experiments in Automatic Writing," by T. Barkworth, to be read by the secretary; "Report of Some Sittings with Mrs. Piper in America," by R. Hodgson. No admittance except by ticket. Extra tickets may be obtained by members or associates on application to the secretary, Richard Hodgson, 5 Boylston Place, Boston, Mass.

-Staff-Commander J. G. Boulton, R.N., who has, since the autumn of 1883 , been engaged in a hydrographic survey of the Georgian Bay, during the past season completed a large proportion of the work yet remaining to be done, being that part of the east coast from Indian Islands to Moose Deer Point, and including the important harbor and approaches of Parry Sound. The part not yet completed comprises the south-east extremity of the bay, lying south-eastward of a line joining Moose Deer Point and Point Rich, of which the most important portion is Matchedash Bay. Two charts have just been issued by the British Admiralty, covering the work done by Capt. Boulton in 1889 . One of these embraces 